\title{
Resisting the rat race
}

\section{Self-sufficiency as a search for resonance in rural Sweden}

\begin{abstract}
When people feel they have to run faster and faster just to keep up, it is a personal experience of the acceleration that characterises late modern society. In reaction, some people attempt to escape "the rat race" by aiming to live self-sufficiently in the countryside. This article presents a text analysis of 35 letters from the magazine Ater, where people share their experiences of moving. The analysis focuses on the authors' motivations for the move, their criticism of mainstream society and their experiences of time, temporality and competing time norms in their new life. Rosa's concepts of acceleration, alienation and resonance, and Adam's concept of abstract and standardised clock time, provide the theoretical framework for the analysis. The study concludes that the authors of letters search for resonance and to a large degree they have also found it, especially since the authors experience their work as meaningful and live according to their ideological values. Self-sufficiency is an individual form of coping, but simultaneously choosing to live differently is a practice of constructive resistance to mainstream consumption and work norms.
\end{abstract}

Keywords: time, temporality constructive resistance, voluntary simplicity, self-sufficiency, resonance, acceleration

PHENOMENA SUCH AS speed-dating, fast food and other demands for increasing tempo in social interaction are some of the acute symptoms of social acceleration which characterise late modern society, according to Hartmut Rosa (2015). Many people experience that they need to run faster and faster just to keep up, and dream of a less hectic life. According to Rosa, the answer to the problems caused by acceleration is not deceleration, but stable axes of "resonance". The defining element in resonant relationships is when people experience that the world listens and responds, for instance in their intimate relationships, when work appears meaningful or when they experience closeness to nature (Rosa 2019).

A group of people which attempts to search for resonance are those who leave city life behind, aiming to live as self-sufficiently as possible in the countryside, searching for greater balance with themselves and the world around them. This study presents a text analysis of 35 "letters" from people in Sweden who have made this move and written about their experiences in the magazine Ater (Swedish for "return”). The let- 
ters are published under the heading "moving out letters" (utflyttarbrev) and are the personal stories of people who have moved to the countryside, and want to share what they have learned with likeminded people. The study investigates two questions: first, in what ways do the authors frame their lifestyle as resistance to mainstream society and the rat race (ekorrhjulet)? Secondly, how do time and temporality appear in the authors' texts when it comes to their new life, and what time related problems and contradictions do they encounter?

The theoretical framework for the analysis of the two questions is Rosa's theory of acceleration, alienation and resonance, as well as the concept of clock time derived from Barbara Adam's work. Adam understands abstract and standardised clock time as one of the most central organising principles in capitalist societies (Adam 1998). Clocks and calendars are the instruments which chop lives into minutes, hours, days, and years. They were essential for regulating the work life which emerged with industrialisation and for the expansion of capitalism (Castree 2009; Hope 2011; Thompson 1967; Thrift 1990[1981]). This perception of time is so central in most people's lives that it is difficult to imagine a life which is not regulated by the clock, since clock time has colonised almost all aspects of modern people's lives (Hochschild 1997; Sørensen, Heikkinen \& Olsson 2019). Nevertheless, people also have a lived experience where one hour might fly by like the blink of an eye, while another hour might seem endless (Rosa 2015).

Abstract clock time and the accompanying acceleration which has driven capitalism has created an enormous wealth in some parts of the world, at the same time as it has had devastating consequences at both a global and individual level. Globally, industrialisation has caused environmental disaster for the planet, while at the individual level capitalism has led to alienation when people spend much of their time on activities they do not really want to do, alongside increased rates of depression and burnout for individuals all over the industrialised world (Rosa 2019).

Below, self-sufficiency is positioned in academic literature as an individual form of constructive resistance, which can be understood as part of a movement for voluntary simplicity. Subsequently, I outline the article's theoretical framework based on Adam's understanding of capitalist temporality and Rosa's critical theory of alienation, acceleration and resonance. This is followed by a section which introduces the data and method. In the main section the results of the text analysis are divided into two themes: 1) the critique of mainstream society and the rat race and 2) the farm as a process. The study concludes that the authors of letters search for resonance and to a large degree they have also found it, especially since the authors experience their work as meaningful and live according to their ideological values. They do develop a different relation to time, but conventional clock time nevertheless seeps into the new life in some aspects and they sometimes experience tensions when different temporalities compete. Self-sufficiency is an individual form of coping, but simultaneously choosing to live differently is a practice of constructive resistance to mainstream consumption and work norms. 


\section{Self-sufficiency as voluntary simplicity}

The phenomenon of self-sufficiency can be related to different bodies of academic literature. Firstly, self-sufficiency is part of a movement of voluntarily simplicity (Grigsby 2004; Alexander \& Ussher 2012). In this movement, people share an interest in reducing consumption for environmental reasons, but voluntary simplicity does not necessarily include an element of self-sufficiency. Voluntary simplicity also has parallels to the growing interest in a minimalist lifestyle, but in minimalism the focus is on minimizing the number of possessions in order to reduce stress for personal reasons, and is less a concern with the environment (Uggla 2019). Likewise, the terms downshifting and voluntary unemployment have been used to describe the phenomena where people (usually voluntarily) work less or switch to less stressful forms of work in order to have more time at their disposal (Hörning, Gerhard \& Michailow 1995; Schor 1999).

The decision to move can also be considered a lifestyle migration (Benson \& Osbaldiston 2016; Benson \& O'Reilly 2009). In Sweden, the general migration pattern is that people move from the countryside to the cities, but in the 1970's some people moved in the other direction for ideological reasons in order to increase self-sufficiency (Holmberg 1998). This "back to the land" movement is known as "the green wave" in Sweden. Sweden also sees a number of migrants from other parts of Europe who move to the Swedish countryside in order to escape stress, overcrowding and environmental risks. Persson (2019) understands this as a form of resistance, but her German and Dutch informants' desire to get away from something is more clearly stated than what they want instead. Persson's informants emphasized the normality of their lives - they live in "normal homes" and have "ordinary jobs", and in this respect, they are very different from the authors of the letters analysed here.

\section{Self-sufficiency as constructive resistance}

The term resistance is frequently associated with riots, revolutions and nonviolent direct action, but within the emerging field of resistance studies, the nuances and variations of different types of resistances are being explored, with concepts such as everyday resistance (Johansson \& Vinthagen 2016; Baaz, Lilja, Schulz et al. 2016) and constructive resistance being applied to more quiet and subtle forms of resistance. Previously I have defined the term constructive resistance as people's attempts to "start to build the society they desire independently of structures of power” (Sørensen 2016:57). Usually the term is used in relation to collective efforts, but according to this definition, constructive resistance can also be carried out by individuals. This distinguishes constructive resistance from the study of prefigurative politics and prefiguration in social movement studies, where the focus is on how movements perform protest or the alternatives they build (Yates 2014; Maeckelbergh 2011).

Explicitly using the term constructive resistance in a recent special issue of Sociologisk Forskning, Sørensen and Wiksell (2019) have theorized the complexity of resistance in relation to temporality. Even when people consciously try to construct ways of 
living and working intended to oppose capitalism and succeed in some aspects, they nevertheless encounter obstacles when different temporalities compete with each other (Cooper 2013; Sørensen \& Wiksell 2019). Using time banks and worker cooperatives as our two illustrative cases, Wiksell and I investigated the ways these two types of organized and collective resistance related to two aspects of the dominant capitalist temporality. The two aspects we analysed were abstract and standardised clock time and the commodification of time, both derived from Adam's (1998) work. Abstract and standardised clock time was essential for the development of capitalism, but now completely dominate almost all aspects of life in late modern societies. It is closely connected to commodification of time, caught by the phrase that "time is money". However, as Adam points out, time is not at all like money, since it cannot be stored or passed on to future generations. Hardly surprising, we found that while the time banks and worker cooperatives did manage to organize their activities differently in one aspect, they might nevertheless reproduce the capitalist temporality in another aspect. In the following analysis, I will pursue some of the same lines of inquiry as Wiksell and I did when it comes to clock time, but in contrast to the previous article which focused on organised collective resistance, the present analysis deals with individual efforts.

\section{Time, acceleration, alienation and resonance}

Wiksell and I (Sørensen \& Wiksell 2019) drew the two concepts of abstract and standardised clock time and the commodification of time from Adam's book Timescapes of modernity (1998). Adam's primary focus in this book is how habitual thinking about temporality affects environmental hazards and industrialised societies' perception of those hazards. She considers time and space closely linked, but while space is visible, time is the invisible "other" which is easily forgotten. Closely linked to abstract and standardised clock time is the pervasiveness of Newtonian science and its linear perspective where complex processes are turned into isolated parts. Clock time is an "atemporal time", because it does not recognize the complexity of life in nature and social organisations. In real life, people experience some days as special, for instance when a new family member is born or someone dies. Human beings have fear or hope for the future and are closely connected to rhythms and cycles of life and death, as elsewhere in nature.

One of the examples that Adam points towards in her work on environmental hazards are the consequences of industrialising agriculture (Adam 1998:128-160). In the not so distant past, the seasons limited what types of food were available in a certain area. In western supermarkets today, consumers expect to find all kinds of agricultural produce "fresh", every day of the year. Food production is an industry completely governed by clock time and commodification of time, integrated into the global economy where "time is money" and where one can speculate in food prices on the stock market. It forces farmers to grow chickens, cattle and pigs as fast as possible, and has led to a wide spread of food hazards such as salmonella and mad cow disease (BSE).

Like Adam, critical theorist Rosa $(2010,2015)$ is interested in temporality in late 
modern society, and how acceleration affects all areas of life, from technical acceleration to the acceleration of social change and the acceleration of the pace of life (Rosa 2015). Social acceleration is a self-propelling process, which leads to a steadily increasing pace in the changes people experience. This acceleration has driven an economic growth which has led to great prosperity in many societies, but it has also had devastating consequences for the environment and an increase in burnout and depression, to mention a few problems. Rosa identifies depression and burnout as a dysfunctional side effect of the social pressure to accelerate, indicating a limit to what human beings can cope with.

In one of his early works on acceleration, Rosa (2010) concluded by describing how acceleration leads to five different forms of alienation in late modern society. First of all, people experience alienation from the space around them; when they constantly move to new places, they no longer feel at home anywhere. Secondly, many items people have around them (furniture, TV, cloth) are frequently replaced with new objects, which means that each item has less value. Third, people become alienated from their own actions when they cannot understand the processes they engage in (for instance how the computer works), or are constantly overloaded with information. Rosa also relates this to how people spend large amounts of time on activities they do not really want to do, and describes vividly how he really wanted to write his book, but instead surfed on the internet and answered emails - an experience that many people can relate to. The fourth aspect of alienation Rosa calls alienation from time. It is well known that time people experience as long (waiting for the doctor) will subsequently take very little space in our memory, while the opposite occurs when people go on an exciting holiday - time is flying, but all the events takes a great deal of memory space. Increasingly, late modern subjects instead experience what Rosa calls "the paradox of time", where experience and memory form a short/short pattern. People can play computer games or watch TV for hours and time flies, but usually it does not become part of their lived experience, leaving little trace in their memories. Finally, Rosa also thinks that people experience self-alienation when they get overwhelmed by all the superficial relations they have to engage in (Rosa 2010).

In his work focused on acceleration, Rosa (2015) also briefly mentions intentional deceleration, which is interesting in relation to resistance. He identifies two forms - one is the slowdown as a strategy of acceleration, where for instance mindfulness and yoga are used to cope with the pace of life. After a short break, people are ready to go on at full speed again. This is a way of coping and not resistance, since the temporary breaks contribute to upholding the accelerating system. The other form is ideologically motivated movements for deceleration, such as the slow food movement and the movement for voluntary simplicity. Rosa is sceptical about their possibilities to spread because the individual cost of deceleration is so high that whoever is "joining a sect, taking over an ecofarm, or plunging into a time-forgetful drug culture risk missing the boat and finding no chance for readmission. When after several years she is ready to return to mainstream society, her resources are hopelessly obsolete" (Rosa 2015:86). Here Rosa is making quite a sweeping claim, and assuming that intentional deceleration based on 
ideology automatically means isolation from the rest of society. As the analysis of the letters from Ater will show, this is not the case at all, at least when it comes to "taking over an ecofarm".

In his latest book, Rosa (2019) brings in "resonance" as the answer to the problems caused by acceleration and alienation. His starting point is that we are "wired" towards longing for resonant relationships, something he describes as a mode of being-in-theworld where people and world respond to each other, and at the same time each speaks with its own voice. Depression and burnout occur when the world has become mute and no longer "speaks" to the subject. A life with many moments of resonance is likely to be experienced as a good life, but there are many paths to resonance and no "one size fits all". Some of the factors Rosa identifies as a hindrance for resonant relationships are acceleration and competition, which instead lead to the aforementioned alienation. The way people experience resonance can be through a horizontal dimension where Rosa mentions relationships with family and friends. Having a partner is one of the most important sources of resonance in late modern societies today according to Rosa, where so many expectations are invested in this one relationship. Likewise, people who have children also have high expectations of these relationships. Secondly, Rosa identifies a diagonal dimension of resonance where he includes areas such as work and education. A typical expectation in late modern society is that work should be experienced as meaningful and fulfilling. Third, Rosa points towards the vertical dimension of resonance, which occurs for instance when people feel connected to nature, God or experience a piece of art that "speaks" to them.

Rosa characterises modern society both as a "catastrophe" and an era of increased sensitivity when it comes to resonance. The catastrophe he associates with the rationality of the Enlightenment and capitalism, which has given humans an instrumentalist attitude towards nature, themselves and each other where every action should have a purpose and be based on "rational" decisions. However, in parallel, modernity has also made humans more sensitive towards resonance, and instilled a longing for resonant relationships in people. Thus, people dream of finding a romantic partner for life and their work to be a place where they can show their full potential. Paradoxically, human beings frequently pursue this desire for resonance through an instrumentalist strategy.

Rosa only briefly considers how the crisis of resonance can be countered in a future "post-growth", society where people might find a better balance between a reified and a resonant relationship to world. Rosa argues that solutions must come from people and cannot be enforced from the top-down, and what he calls for has some parallels to the concept of constructive resistance. This makes it interesting to look at the longing for self-sufficiency in relation to the concept of resonance, and to assess self-sufficiency's potential to develop from individual oases of resonance into more widespread structures. 


\section{Data and method}

The data in this study consist of 35 letters from Swedish families who decided to move to the countryside in order to live a more self-sufficient life, and have chosen to share their personal stories about the experiences with the other readers of Ater. The letters were published in the Swedish magazine Ater between 2014 and 2018, and vary in length between one and six A4 pages. Ater is a quarterly printed magazine dedicated to self-sufficiency. One can buy a subscription through www.alternativ.nu, which is a Swedish web forum dedicated to self-sufficiency with more than 45,000 members. The forum does not define self-sufficiency, but the purpose states: "Here you can find help to become more self-sufficient by reading, asking and discussing cultivation for self-sufficiency, animal keeping, handicraft, building, living, preservation and much else someone self-sufficient need to know" (alternativ.nu 2019). Likewise, most articles in the printed magazine $\AA$ ter provide practical advice about the same topics. A recent MA thesis which analysed the magazine concluded that it was a community of people who share a vision of an alternative modernity, and that the magazine focuses on practice in the here and now. Ater is critical of the focus on effectiveness and consumption in modern societies, and the lack of meaningfulness in many jobs (Crole-Rees 2018).

The letters I have analysed were published under the headings "moving out letters" and "Mie and Erika's beginner letters". Although these are slightly different because the latter are shorter (only one page each) and the two authors link back to what has been said in their previous letters, this has not made any difference for the analysis. The letters are written in the first person in the style of a letter you would write to a friend. Most of the letters focus on what kinds of buildings the farm has, renovations undertaken, what kind of animals the authors and their families have tried to keep, and the struggles with establishing vegetable gardens. However, almost everyone also includes elements which are especially interesting for this study, when the authors reflect on the reason for moving, quality of life, the meaning of the new lifestyle, and explicitly talk about time in various ways.

It is not possible to know how representative the people are who aim to live selfsufficiently and write about it in Ater. They are a self-selected group, and the literary genre the letters belong to sets limits to what it is possible to learn from them. Naturally, they do not include any examples of people who have given up on self-sufficiency and moved back to the city. Reasons for giving up are an obvious avenue of future research, but this would require a different type of data.

The authors of the articles in Ater are very different from each other - there are singles and couples, parents and voluntarily childless, a great variety in terms of age, gender, education and how long they have lived on their farm. Some rely almost completely on their farm, others have incomes as employees or own their own businesses. With self-sufficiency, the aim is to produce enough food and other necessities to satisfy their own needs, or for those who own a business, to sell just enough to maintain a life in voluntary simplicity. A few authors are very strict followers of the principle of 
self-sufficiency, but most are quite pragmatic and aim to be self-sufficient in as many areas of life as possible under their current circumstances.

The texts provide a unique glimpse into the life-world of the authors, and what they consider important to share with likeminded people. Because the articles were not written with the purpose of being analysed by a researcher, I found it most ethical not to name the authors, although they write under their full names in a publicly available magazine. Each quote from the magazine is followed by a reference like this: (2014-2B). Here, 2014 indicates the year the letter was published in Ater, and 2 refer to issue number 2 of that year. The $B$ indicates that this is the second letter in this issue. Letters where the reference ends with an $\mathrm{A}$ or a $\mathrm{C}$ refer to the first or third letter in the issue, respectively.

The major advantage of using a type of data which is constructed for other purposes than research is that it has not been influenced by the researcher's agenda and coconstruction of data (Kvale \& Brinkmann 2009), as would have been the case with qualitative interviews. Instead, the letters naturally include reflections about time, work, money, life choices, and critique of mainstream society, which are relevant to the research questions. The disadvantage of natural data is that interviews might have generated a richer dataset and given the informants an opportunity to elaborate on these issues. However, the letters do provide plenty of material for analysis.

I have analysed the texts inspired by the systematic approach of qualitative content analysis (Boréus \& Kohl 2018; Schreier 2013) and phenomenological analysis of qualitative data, using first and second cycle coding (Miles, Huberman \& Saldaña 2014; Kvale \& Brinkmann 2009). I started out exploring six letters with an open mind, using a phenomenological point of departure in order to understand the lifeworld of the authors when it came to their motivations for moving to the countryside and their relationship with time. Based on this inductive stage I developed a coding list which was supplemented with a theoretically informed code originating from Rosa's early writing on alienation and resonance (Rosa 2010). The codes were then applied to all the letters which were published between 2014 and 2018, a total of 35 . The codes are not mutually exclusive and many text sections where the author explicitly reflects on their choice to move have more than one code. All the texts were coded manually, using the qualitative data analysis software NVivo to keep track of texts and codes.

During the analysis of the articles in Ater, I developed two main themes (presented in the following section), the first of which is called critique of mainstream society and the rat race. Here I introduce the letter authors' explicit motivations for changing lifestyle and draw on Rosa's theory of acceleration, alienation and resonance to present the findings. The second theme, the farm as a process, catches the temporalities of the authors' new lifestyle and the partly contradicting temporalities are presented in relation to Adam's understanding of clock time. Since the present study's focus has been on temporality and resistance, there are many themes not included in the presentation below, such as the efforts spent on renovating houses, the way the authors deal with setbacks, the learning of new skills and how they think they are perceived by others. 


\section{Findings from the Ater articles}

\section{Critique of mainstream society and the rat race}

Those authors of letters who explicitly say something critical about mainstream life as a motivation for moving mention consumption, worries about the economy and especially concern for the environment, alongside the well-being of animals for food production, as major reasons for their life change. Thus, they are very much in line with Adam's critique of the globalised and industrialised food production where all types of food are available all year round. Although they do not explicitly express Adam's sophisticated timescape analysis, the essence is similar; conventional food production is completely unsustainable, filled with risks and hazards, and the authors want to limit their involvement in this. Some express this concern at a societal level, such as this author of a letter who sees self-sufficiency as a challenge to the present economic system:

But the wheels have to turn [some might say]! Yes, we are probably a danger to society since we don't contribute to economic growth as we are supposed to. But in my eyes, we build something that is much more permanent than Sweden's GDP. (2017-3A)

Another author explains how they have an ideological conviction that this lifestyle is environmentally sustainable and how the alternative had been dumpster diving in the cities:

Why do we do this? Besides that both of us like to be in nature, for both of us it is a great deal about ideological conviction. We see small scale self-sufficiency as one of few environmentally sustainable alternatives. Additionally, we like the thought of having power over our own time and our own lives. If we had lived in the city we would probably have occupied empty houses and picked up all our food from ICA maxi's container. (2014-2B)

However, some explain their choice in relation to a more personal sphere with concern for their children's future, while still making a close link to environmental sustainability and criticising industrialised food production:

In addition to leaving the rat race and live and work for our own sake, there are other factors that influence our decision. [Crop] spraying, environmental poisons and all these animals that suffer because of the ravaging caused by the industry, its desire to earn money. We want to be able to give our children food which is as free from poison as absolutely possible and meat from animals that have had a good life. To teach them to respect all living beings around us. For us this has become the most important carrot. Not to live in the consumption society. (2014-1A) 
The letter author below describes the alienation and muteness the couple felt in their "previous" life, which they experienced as meaningless and competitive. Despite having all modern comforts and so-called freedom, it felt like a prison:

Is life a competition, and if so, who do I compete against and why do I want to win? [...] Do I experience that what I do as meaningful? [...] Our whole life with self-sufficiency is grounded in a modern reality that constantly made us ask questions such as the above. We experienced a sense of inner emptiness in spite of the fact that the outer world was full of constant impressions, updates, meetings and activities. [...] When we met as woofers at an organic farm in New Zealand we were both lost. Running from something, but what? My best way of expressing the answer is: from what is called the rat race, and lack of mindfulness and compassion for each other and earth. An escape from a way of living, thinking and existing in grey concrete that we grew up with in the modern, comfortable western world. It is called freedom, but it felt like a prison. (2018-1B).

Although this letter author is not referring to Rosa's concepts of alienation and acceleration, it sounds like a personified version of his descriptions of life in the late modern world. The experience of emptiness and meaninglessness express how the world is mute and does not speak, in spite of everything the modern world has to offer. The author questions competition and expresses how they felt disoriented and lost, alienated from their own actions as Rosa would say. Likewise, it is no coincidence that several of the authors above explicitly link their choice of lifestyle to time, with expressions such as "control over our own time", "time has become the most important carrot" and "stepping out of the rat race". The rat race is a frequently occurring metaphor for the accelerating society, where people run and run without getting anywhere. Every author who writes about this theme without exception link the control of their own time to quality of life, such as this author of a letter:

To be self-employed and engaged in cultivation has involved a lot of hard work. Today we control our own time and that gives an enormous freedom. Hard work is less burdensome when the fruit of our labour is retained by ourselves. That is what we call quality of life! (2014-1C)

As is apparent from the last quote, the lifestyle of self-sufficiency is hard work, and the honesty from this author of a letter sums it up: "What is the purpose? It is an incredible amount of work and a very restricting life to be self-sufficient" (2017-3A). The author continues with a long list of answers to why it is worth it, starting with: "The great pleasure. To cultivate and eat what you have harvested yourself is an enormous satisfaction. The finest luxurious potatoes in exclusive packaging from the shop doesn't compare with your own newly harvested".

Several of the quotes above indicate a pattern which is repeated in the texts - the new life is experienced as meaningful, one of the most important aspects of experiencing 
resonance according to Rosa. Another frequently recurring theme is the balance between time and money. The more one works outside of the farm in order to earn money, the less time there is for developing the farm. The authors are highly aware of this dilemma, and have made conscious decisions to have more time at their own disposal than money:

In our family, we have talked a lot about the connection between time and money - more money often means less time as a family, less money means more time but fewer opportunities to buy new things or travel far. (2014-4A)

Here the author suggests how family life is important, something which is often mentioned by authors with children. Although this particular quote does not include the quality of the family relations, spending time together provides a ground for a resonant relationship in the horizontal dimension of Rosa's theory. In mentioning the limited possibilities for buying new things, this letter author also hints at another important aspect of the lifestyle, which is about consumption. The emphasis on recycling and the awareness of limited recourses associated with self-sufficiency means that several authors write about a different relationship with their belongings than what is found elsewhere in the consumption society. An obvious source of a close relationship with their houses is the time and energy spent on renovation, but also when it comes to small and daily items, the authors themselves perceive that their relationship to things differs from the mainstream, as this author of a letter indicates here:

My husband and I have a common wish list on the fridge, it includes everything from rubber boots and broom to a computer battery and a dough-scraper. Yesterday the whole family went out to pick mushrooms and finally us grown-ups also had rubber boots! For us it is about prioritising, maybe it sounds stingy not to be able to buy rubber boots, but instead we have prioritised to have dog and cat, and now we can finally go to the forest with both the boots and the dog! And we appreciate it! All the little things. It makes me happy to sweep the henhouse now that the broom is finally here instead of other temporary solutions. If I had worked a lot, maybe didn't have children and bought those rubber boots as one thing among many, would I really appreciate them as much as I do now? (2014-4A).

According to Rosa, the lack of relation to things which are constantly replaced is one source of alienation in the accelerating society, but this letter author seems to describe a quite close relationship with the new rubber boots, thanks to her awareness that she cannot take them for granted and because she is aware how much paid work she needs to do in order to pay for them. It is clear that living according to her values means that she and her family have less money, but the example also hints at how people's motives influence how they experience consumption of material goods.

To sum up this theme in relation to Rosa's theories of acceleration, alienation and resonance, it is hardly a surprise that the people who chose such a different lifestyle 
have an explicit critique of the norms in mainstream society, which are associated with meaninglessness, overconsumption and looming environmental disasters. Although one might not be surprised by this finding, it is meaningful to investigate how deeply the authors are affected by this feeling of meaninglessness, and how far-reaching the steps are that some of them are willing to take in order to restore meaningfulness in their lives. The authors describe mainstream society as an alienating place that forced them to spend too much time on meaningless activities and how they could not find a balance in life. Thus, they engage in a form of resistance when they chose to be "rich in time rather than money" (2014-4B), as one author explained to their children when they asked if the family was poor. Moving to the countryside and giving self-sufficiency a major place in their life was clearly a search for stable axes of resonance, which they have now found in the different dimensions. Although all authors do not describe resonant relationships in all dimensions, the texts indicate a possibility for finding resonance in the horizontal dimension through more time with family, the diagonal dimension by engaging in meaningful work, and the vertical dimension by living according to one's ideological values and connected to nature. Although the new life involves a lot of hard work and is certainly not without its problems, the people who are aiming to live with some degree of self-sufficiency experience it as highly meaningful and fulfilling, which is the most important source of resonance repeatedly brought up in the letters.

\section{The farms as a process}

Many of the authors of letters describe time in a way I will refer to as "process oriented". With the term "process", I mean how the authors understand their farm as a place which will and should develop with time, but also how they describe a life in touch with the changing seasons and connected to natural rhythms of life and death and without stress. Their adoption of this process-oriented understanding of time and attempt to live according to it is an expression of the same critique of how abstract and standardised clock time colonise so many aspects of late modern societies, as Adam describes in academic terms (Adam 1998). Included in the process-oriented approach is an implicit ideal regarding how life should not include the level of stress they experienced in their "old" lives. However, as the analysis will reveal, reality on the farm is not always resembling the ideal, and their lives are still filled with contradictions when clock time temporality nevertheless encroaches on their lives.

The process orientation is evident in the letters both when it comes to organising the day, the cycle of the year, and how the authors view their farm in relation to the past, present and future. Although they might have a certain plan for how they would like the farm to develop, this plan is constantly revised and circumstances force them to make adaptions. The authors frequently describe how the vegetable garden grows and expands, how they acquire new types of animals or new breeds, and how the farm changes: 
The farm has changed all the time and that feels good! We have built, demolished, cultivated, put up fences and cleared. All of it in order to make the most of the place where we live. We have acquired new kinds of animals, but also given up on others in order to prioritise those that fit with our farm and us. (2014-2A)

Several authors mention how their interest in cultivation has changed with time from being a bit unsystematic simply for pleasure, to become something they plan systematically to put food on the table.

In western societies, the majority of the population eat meat, but very few have tried to kill an animal in order to get food on the table. However, slaughter is a necessity for meat eaters who want to live self-sufficiently, and several authors mention how they slaughter their own animals in order to spare the animals the stress of transportation to the slaughterhouse. For some, this is a quite burdensome part of their new lives, although they see it as a natural part in a life which is closer to the biological rhythms of life. The two authors who exchange "beginner letters" about self-sufficiently mention slaughter several times, and how it does not come easy:

The blue ducks have grown considerably and we have started to prepare ourselves mentally for the duck slaughter [...]. Killing is difficult, the ducks have become real personalities and at the moment it feels a lot easier to kill a rooster than a duck drake. (2015-4)

Life on the farm is often organised so the changing seasons guide what needs to be done, and what kind of food is available. This is how things used to be before food production became industrialised and globalised in a way that makes it possible to have all kinds of plastic wrapped food available "fresh" all year round in supermarkets in affluent societies (Adam 1998). For the authors, the seasons influence the tempo on the farm, where early summer might be a stressful time as this author of a letter explains:

Early summer. The words sound so hopeful. The possibilities are endless, everything can still happen. It is also a quite stressful time, plants need to be re-potted or planted out, seeds sown, animals moved at the same time as there are grill nights, school graduations, summer parties and other events. (2015-3B)

Although the relationship with and dependence on the seasons means that many authors live a life which appears to be more in tune with the seasons and natural rhythms of life and death than most people in late modern societies, for some authors of letters paid work still seems to be the norm against which everything else is measured. In the quote below, the author starts out by talking about the luxury of being "completely at leisure" for almost three months. What is meant is that they are not working in their paid jobs, because in the next sentence it becomes apparent that they have worked hard on the farm all this time: 
We have had a lot of time together the whole family, we have all been completely at leisure for almost three months. Incredibly luxurious! We have worked on the farm from dusk to dawn, falling asleep exhausted and happy. (2015-4B)

Another author introduces a long description of how the work on the farm is divided up according to the seasons: "Our leisure time is guided by what needs to be done outside" (2017-3A). However, the list the author continues with is so full of activities that most people would hardly call it "leisure", but rather time that is not occupied with paid work outside the farm. These two examples make it obvious that even for some of these authors who have made a very conscious decision about priorities in their life, paid work is nevertheless the norm everything else is measured against. It seems paradoxical that paid work norms are so important at the same time as the authors strive towards a more process-oriented approach to life.

Life on the farm, which for most authors of letters means less paid work, also means that the perception about paid work can change considerably, becoming an exceptional activity associated with something pleasant. This quote also illustrates that for some authors, completely avoiding paid work outside the farm is not a goal at all:

To work part time and suddenly remember "oh yeah, tomorrow I have to work" is an amazing feeling, that paid work is no longer the rule but the exception. And the paid work is rather pleasurable, it is fun to rub your nails and wash the clay out of your hair, change into civilian clothing and go and meet nice colleagues. $(2018-1 \mathrm{~A})$

This quote also indicates that the author has no intention of isolating herself from the rest of society. Although a life with more self-sufficiency might be different from a mainstream life, the large majority of the authors maintain close ties to the rest of society.

Another way that conventional temporality seems to seep into life on the farm is when it comes to efficiency, an essential aspect of clock time and a driving force in capitalism. Several authors write about being as efficient as possible with time in order to be able to do everything they want. However, this contradicts their perception that this is not an ideal in the process-oriented life they strive towards. The authors seem to be torn between a wish for a less hectic life in balance with nature and expectations that they accomplish tasks in an efficient way. For instance, people start out with ideals about wanting to support old breeds of chickens and sheep, but end up realising that if the goal is to put food on the table, other types might be more efficient. Others discover that to have enough to eat, they need to plan ahead regarding what needs doing and when, as this quote describes:

Since we are working in our paid jobs quite a bit this summer we try to plan the harvesting and picking, in order to have time. If I know that I need to take care of the gooseberry harvest a particular week, then we avoid planning another project 
at the same time. Maybe it sounds extremely boring to know in advance what is to be done when, but in any other job you plan and have goals, so why not with self-sufficiency? That is what is going to provide food in the year to come? I have a book where I have tried to note how much we have harvested of what the last two years, and how much it gave in the form of juice, jam and other things, and approximately how long it lasted. (2015-3D)

That planning is necessary in order to run a farm will not surprise anyone who has tried, but this quote suggests an ambivalence, indicated by the phrase "maybe it sounds extremely boring", which suggest that the author's ideal is having greater flexibility. There is a hint of sadness in realising that life on the farm also requires a temporal orientation far from the ideal, even if it is experienced as more meaningful to have a hectic life on the farm than a hectic meaningless paid job.

Another temporal aspect of the letters is their orientation towards the future. They are filled with both long- and short-term plans and dreams about new animals, new gardens, renovations to be undertaken or starting their own business, as this author mentions:

Micke is charging his batteries to make the jump and start his own business with the farm, selling farm products like vegetables, honey, handicrafts etc. Let that take the place of paid work. Be more on the farm and focus on that. We plan to get sheep next year. (2018-2A)

But time of course sets limits to how fast change can happen and what it is possible to do in a season, and limiting oneself might be a challenge when the wishes are many, as this writer of a letter reflects on:

My thoughts have shifted from wanting to do so much myself to scaling down and doing what we are good at. I have to stop and remind myself that we have lived here for half a year. We have to grow with the experiences. So now we prioritise the chickens, bees and to make the greenhouse in order! But we have started to consider meat rabbits. (2014-3B)

In the process of developing the farm, those who move out are inevitably going to make mistakes, or experience that plans have to be changed or abandoned. Thus, the letters include numerous examples of catastrophes and setbacks. The authors do not seem to hesitate to share such examples, but these stories are almost always presented within a frame of optimism and a spirit of "get up on the horse again" and keep trying. Not a single author is talking about giving up or describing how the family ended up moving back to the city, or giving up on the idea of self-sufficiency.

To sum up this theme in relation to Adam's understanding of clock time which dominates late modern society, the authors' lives clearly divert from the standard in many ways. The letters are characterised by a process orientation which take many dif- 
ferent forms; the authors follow the seasons and natural rhythms of life and death, and they learn along the way as their farms continuously evolve and change. However, the temporality from the accelerating society around them also seeps into their accounts. Paid work is frequently the norm everything else is measured against, and the idea of spending time effectively is not unusual in the letters. Not "wasting time" has many similarities with the "time is money" ideology that drives capitalism, and the letters signal an ambiguity when the authors reflect on the need for efficiency when aiming to put food on the table through their own hard work. In relation to Rosa's theory of acceleration, the analysis of the letters presented in "the farm as a process" also has an interesting finding. As mentioned in the theory section above, Rosa (2015) writes that ideologically motivated deceleration are automatically islands of isolation. The letters analysed here point in a different direction. The quote from the author who enjoys her part-time paid work, as well as the author who gets stressed by the things that need to be done on the farm while she has to attend "grill nights, school graduations, summer parties and other events", suggest that these authors have no intention of isolating themselves. However, maintaining these ties create tensions when it comes to temporality, since their idea of what a process orientation ought to mean might collide with their own and other's expectations regarding what should be accomplished in a certain amount of time.

\section{Conclusion: Searching for resonance through individual constructive resistance}

The authors of the texts in Ater do not use Rosa's vocabulary, but their descriptions of mainstream society indicate that they consider it an alienating place, and they are critical of the consequences of living in a competitive and accelerating society. They point towards environmental destruction, little control of time, and the obsession with consumption as some of the problematic sides of society. These are all aspects of what Rosa calls the catastrophic side of modernity. However, at the same time modernity has also produced a new sensitivity to resonance, an expectation that life has more to offer than just survival. In the letters, this becomes obvious through the longing for a meaningful life without harmful stress. For the authors of the letters, the answer to the problematic sides of modernity has been self-sufficiency, which provides meaningfulness and a life in balance with nature, themselves and the surrounding society. The authors describe a close relationship with the food they produce, the animals they keep and the farm they live on. The lifestyle gives them opportunity to develop resonant relationships with their partners and children in the horizontal dimension described by Rosa, when they spend more time with the immediate family than what is the norm. The work they carry out as farmers and in their other businesses creates resonance in the diagonal dimension, when they experience their hard work and effort as meaningful. Resonance also occurs in the vertical dimension when they feel connected to nature and live according to their ideological ideals. For Rosa, the 
answer to the problems caused by acceleration is not deceleration, but resonance. The authors of the texts in Ater suggest a combination has been the solution to them; some deceleration in the form of a more process-oriented approach to life is necessary in order to be able to create room for resonance.

A life with self-sufficiency is certainly not the solution for everyone, but for some people it might be one possible way to live in what Rosa (2019) refers to as the "postgrowth society". To Rosa, this is a society where the economy is still capable of growing in order to meet certain needs, but where economic expansion is no longer the order of the day. Instead, what counts will be the quality of relationships and stability of the axes of resonance.

When the Ater authors work on and develop their farms, they are engaged in a constructive form of resistance. They not only criticise the problematic aspects of mainstream society, but try to live differently in the here and now. With voluntary simplicity on the rise and an increased awareness regarding wealthy societies' need for a controlled and planned transition to a post-growth society, these pioneers have important lessons to share with the rest of society. Thus, the Ater authors' lifestyles have two sides. First, it is a way for the authors themselves to cope, to find a way of living in the modern world which is acceptable at a personal level. Secondly, their voluntary simplicity also has a societal aspect of resistance, when their lifestyle in practice diverts drastically from mainstream norms about consumption and work. They create small islands of a post-growth society, which might inspire others searching for both resonance and environmental sustainability. Such "islands" might turn out to be extremely important in the aftermath of the economic crisis which started in 2020 with the emergence of the Coronavirus, and the drastic measures taken by governments to slow down the rapid spread of the virus. Although many politicians and economists will attempt to "go back to normal" as it was in 2019, the crisis is also likely to cause an increasing number of people to search for alternatives and strive for societies which are more resilient and less vulnerable to disruptions of the economy.

Rosa is sceptical of the possibility for the ideologically motivated islands of deceleration to spread because of people's fear of losing out if they take such a drastic step. However, the letters from Ater do not suggest that the authors are isolating themselves from the rest of society or that those who move out are worried they will lose out. Although a few authors appear to live relatively isolated, many of them seem quite satisfied with having part-time paid work outside the farm. Rather than aiming for isolation, they are trying to decelerate at an individual level to make room for resonance. However, at the same time their individual choices are also living testimony to other people that it is possible to live differently without cutting all ties to the rest of society. In the transition to a post-growth society, this appears to be a very important finding from the analysis of the letters - that it is possible to live a more balanced and decelerated life without having to isolate from the rest of society. At the moment, those who choose this lifestyle are too few to be any threat to conventional practices emphasising economic growth, but this might change. Findings from the text analysis also illustrate that resistance is not necessarily a question of either-or, something which 
was also emphasised by Wiksell and I in our study of temporality in more organised forms of resistance (Sørensen \& Wiksell 2019. In terms of time and temporality, understanding the farm as a process is one of the most dominant themes in the texts. The seasons do guide what needs to be done and when, but it is also in this theme the competing temporalities in their lives emerge. There is in ideal about how life on the farm should be flexible and stress-free, but in contrast there is a reality where paid-work norms sneak into descriptions of work on the farm, and the authors discover with sadness that time efficiency is sometimes necessary in order to accomplish their dreams for the farm. This also means that these authors, like everyone else, sometimes pursue resonance through an instrumentalist approach. That instrumentalism occasionally takes over in the search for resonance is a paradox pointed out by Rosa, and not even the idealist letter writers can escape this paradox.

\section{References}

Adam, B. (1998) Timescapes of modernity: The environment and invisible hazards. London: Routledge. https://doi.org/10.4324/9780203981382

Alexander, S. \& S. Ussher (2012) "The Voluntary Simplicity Movement: A multinational survey analysis in theoretical context", Journal of Consumer Culture 12 (1):66-86. https://doi.org/10.1177/1469540512444019

alternativ.nu (2019) "Startsida”, https://www.alternativ.nu/index.php (accessed 20 October 2019).

Baaz, M., M. Lilja, M. Schulz \& S. Vinthagen (2016) "Defining and analyzing 'resistance': Possible entrances to the study of subversive practices", Alternatives 41 (3):137-153. https://doi.org/10.1177/0304375417700170

Benson, M. \& K. O’Reilly (2009) "Migration and the search for a better way of life: A critical exploration of lifestyle migration”, The Sociological review 57 (4):608-625. https://doi.org/10.1111/j.1467-954X.2009.01864.x

Benson, M. \& N. Osbaldiston (2016) "Toward a critical sociology of lifestyle migration: Reconceptualizing migration and the search for a better way of life", The Sociological Review 64 (3):407-423. https://doi.org/10.1111/1467-954X.12370

Castree, N. (2009) “The spatio-temporality of capitalism”, Time \& Society 18 (1):2661. https://doi.org/10.1177/0961463X08099942

Cooper, D. (2013) “Time against time: Normative temporalities and the failure of community labour in Local Exchange Trading Schemes", Time \& Society 22 (1):31-54. https://doi.org/10.1177/0961463X11422279

Crole-Rees, C. (2018) Tillbaka till framtiden: (Ett studium av) nejsägande framtidsrevolutionärer. Linköping: Department of Social and Welfare Studies, Linköping University.

Grigsby, M. (2004) Buying time and getting by: The Voluntary Simplicity Movement. Albany: State University of New York Press.

Hochschild, A.R. (1997) The time bind: When work becomes home and home becomes work. New York: Metropolitan Books. 
Holmberg, C. (1998) Längtan till landet: Civilisationskritik och framtidsvisioner $i$ 1970-talets regionalpolitiska debatt. Gothenburg: Department of Historical Studies, Gothenburg University.

Hope, W. (2011) "Crisis of temporalities: Global capitalism after the 2007-08 financial collapse”, Time \& Society 20 (1):94-118. https://doi.org/10.1177/0961463X10392735

Hörning, K.H., A. Gerhard \& M. Michailow (1995) Time pioneers: Flexible working time and new lifestyles. Cambridge: Polity Press.

Johansson, A. \& S. Vinthagen (2016) "Dimensions of everyday resistance: An analytical framework", Critical Sociology 42 (3):417-435. https://doi.org/10.1177/0896920514524604

Kvale, S. \& Brinkmann S. (2009) InterViews: Learning the craft of qualitative research interviewing. Los Angeles: Sage Publications.

Maeckelbergh, M. (2011) "Doing is believing: Prefiguration as strategic practice in the alterglobalization movement”, Social Movement Studies 10 (1):1-20. https://doi.org/10.1080/14742837.2011.545223

Miles, M.B., A.M. Huberman \& J. Saldaña (2014) Qualitative data analysis: A methods sourcebook. Thousand Oaks: Sage.

Persson, L. (2019) "Lifestyle migrants or 'environmental refugees'? - Resisting urban risks", Population, Space and Place 25 (7):e2254. https://doi.org/10.1002/psp.2254

Rosa, H. (2010) Alienation and acceleration: Towards a critical theory of late-modern temporality. Malmö: NSU Press.

Rosa, H. (2015) Social acceleration: A new theory of modernity. New York: Columbia University Press.

Rosa, H. (2019) Resonance: A sociology of our relationship to the world. Cambridge: Polity Press.

Schor, J.B. (1999) The overspent American: Why we want what we don't need. New York: HarperPerennial.

Sørensen, M.J. (2016) "Constructive resistance: Conceptualising and mapping the terrain", Journal of Resistance Studies 2 (1):49-78.

Sørensen, M.J., S. Heikkinen \& E.A. Olsson (2019) "Time, power and resistance", Sociologisk Forskning 56 (3-4):197-207.

Sørensen, M.J. \& K. Wiksell (2019) "Constructive resistance to the dominant capitalist temporality”, Sociologisk Forskning 56 (3-4):253-274.

Thompson, E.P. (1967) “Time, work-discipline, and industrial capitalism”, Past \& Present 38 (1):56-97. https://doi.org/10.1093/past/38.1.56

Thrift, N. (1990[1981]) "The making of capitalist time consciousness", 105-129 in J. Hassard (Ed.) The sociology of time. New York: Palgrave Macmillan. https://doi.org/10.1007/978-1-349-20869-2_8

Uggla, Y. (2019) "Taking back control: Minimalism as a reaction to high speed and overload in contemporary society", Sociologisk Forskning 56 (3-4):233-252.

Yates, L. (2014) "Rethinking prefiguration: Alternatives, micropolitics and goals in social movements". Social Movement Studies 14 (1):1-21. https://doi.org/10.1080/14742837.2013.870883 


\section{Acknowledgements}

I would like to thank Brian Martin, the anonymous reviewers and my sociology colleagues at Karlstad University for useful comments at various stages in the work on this article. Thanks also to Kristina Boréus for stimulating conversations regarding text analysis and Craig Brown for proof-reading assistance and insightful solutions to translation challenges.

\section{Author}

Majken Jul Sørensen is an Associate Professor of Sociology at Karlstad University, Sweden. Her research focuses on everyday and constructive resistance, nonviolent social movements, humour and political activism, as well as people's agency and ability to create change from below.

\section{Corresponding author}

Majken Jul Sørensen

Karlstad University

The department of social and psychological studies, 65188 Karlstad, Sweden majken.jul.sorensen@kau.se 